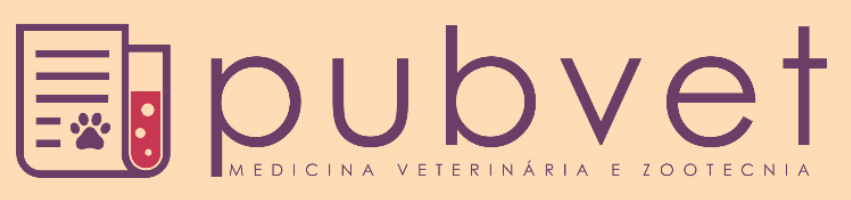

https://doi.org/10.31533/pubvet.v15n03a773.1-13

\title{
Maedi-Visna: aspectos gerais e impactos na ovinocultura
}

\author{
Naianne Celeste Nunes Saraiva ${ }^{\bullet}$, Izabelle Silva Rehfeld ${ }^{\circ}$, Elisa Helena Paz Andrade ${ }^{3 *} \bullet$ \\ ${ }^{1}$ Médica-veterinária, com Pós-graduação em Defesa Sanitária e Tecnologia e Inspeção de Produtos de Origem Animal com Ênfase em \\ Legislação pelo Ifope Educacional - Universidade Cândido Mendes, Rio de Janeiro, RJ, Brasil \\ ${ }_{2}^{2}$ Professora da Faculdade Presidente Antônio Carlos (FUPAC/UNIPAC), Campus Conselheiro Lafaiete - MG, Brasil e Médica Veterinária \\ Oficial do Ministério da Agricultura, Pecuária e Abastecimento (MAPA), Belo Horizonte - MG, Brasil. \\ ${ }^{3}$ Professora da Universidade Federal de Minas Gerais, Departamento de Inspeção e Tecnologia de Produtos de Origem Animal, Belo \\ Horizonte-MG, Brasil. \\ *Autor para correspondência, E-mail:elisahpandrade@yahoo.com.br
}

Resumo. O objetivo desta revisão é abordar os diferentes aspectos da Maedi-Visna, doença de evolução crônica, multissistêmica, causada por um vírus do gênero Lentivirus e família Retroviridae. Acomete pequenos ruminantes, com maior ocorrência em ovinos e está amplamente distribuída no mundo e no Brasil, causando sérios problemas econômicos para a ovinocultura. A transmissão do vírus ocorre principalmente pela via respiratória, por meio de aerossóis, e pela via digestiva com a ingestão de colostro e leite contendo o vírus. Os animais infectados desenvolvem um quadro de emagrecimento progressivo, embora a maioria seja assintomática, podendo ainda apresentar pneumonia, artrite, mastite e encefalite. Por se tratar de uma enfermidade de caráter crônico, na qual a maioria dos animais dificilmente apresenta sinais clínicos, é recomendado que o diagnóstico seja confirmado por meio de exames laboratoriais que têm por objetivo a deteç̧ão de anticorpos ou a identificação do agente etiológico. Não existe vacina e não há tratamento específico eficaz para essa doença, sendo assim as práticas de manejo adotadas para a prevenção desta enfermidade se tornam cruciais, a exemplo do descarte de animais positivos associado à separação das crias de fêmeas positivas ao nascimento.

Palavras chave: colostro, Lentivirus de pequenos ruminantes, ovinos

\section{Maedi-Visna: general aspects and impacts on sheep farming}

Abstract. The purpose of this review is to cover the different aspects of Maedi-Visna, a chronic, multisystemic disease caused by a virus of the genus Lentivirus and family Retroviridae. Small ruminants are affected, with a higher occurrence in sheep. It is widely distributed throughout the world and in Brazil, leading to serious economic problems in sheep farming. Transmission of the virus occurs mainly through the respiratory route, through aerosols, and through the digestive route with the ingestion of colostrum and milk containing the virus. Infected animals become progressively slimmer, although most of them are asymptomatic and pneumonia, arthritis, mastitis and encephalitis may be present. Because it is a chronic disease, it is more difficult to find clinical evidence, so the diagnosis should be confirmed by laboratory tests based on antibody detection or identification of the etiological agent. There are no vaccines or treatments to prevent the disease, therefore management practices should be adopted to prevent it, as discarding positive animals associated with separating offspring from positive females at birth.

Keywords: Colostrum, Lentivirus of small ruminants, sheep 


\title{
Maedi-Visna: Aspectos generales e impactos en la ovinocultura
}

\begin{abstract}
Resumen: El objetivo de esta revisión, es abordar los diferentes aspectos del Maedi-Visna, enfermedad de evolución crónica, multi sistémica, causada por un virus de género Lentivirus y familia Retroviridae. Afecta a pequeños rumiantes, con mayor frecuencia en ovinos y está ampliamente distribuido en el mundo y en Brasil, causando serios problemas económicos en la ovinocultura. La transmisión del virus ocurre principalmente por la vía respiratoria, por medio de aerosoles y por la vía digestiva con la ingestión de calostro y leche conteniendo el virus. Los animales infectados desenvuelven un cuadro de enflaquecimiento progresivo, aunque la mayoría sea asintomática, pudiendo todavía presentar neumonía, artritis, mastitis y encefalitis. Por tratarse de una enfermedad de carácter crónico, en la cual la mayoría de los animales difícilmente presentan signos clínicos, es recomendado que el diagnóstico sea confirmado por medio de pruebas de laboratorio que tiene por objetivo detectar los anticuerpos o la identificación del agente etiológico. No existe vacuna y no hay tratamiento específico eficaz para esta enfermedad, siendo así las prácticas de manejo adoptadas para la prevención de esta enfermedad se tornan cruciales, por ejemplo, el descarte de animales positivos asociado a la separación de las crías de las hembras positivas al nacimiento.
\end{abstract}

Palabras clave: Calostro, Lentivirus de pequeños rumiantes, ovinos

\section{Introdução}

No Brasil, a criação de pequenos ruminantes vem se solidificando e se tornando uma das principais atividades do setor pecuário, apresentando um grande potencial de crescimento e expansão para a produção de carne, leite, lã, pele e seus derivados (ANUALPEC, 2020). Segundo dados do Instituto Brasileiro de Geografia e Estatística (IBGE), o efetivo de caprinos e ovinos, em cabeças, no país em 2018, foi de 10.696.664 e 18.948.934, respectivamente (ANUALPEC, 2020). Dentro do cenário mundial, a criação desses animais tem apresentado uma mudança de paradigma, saindo de uma atividade de subsistência para uma atividade empresarial especializada (Mazzinghy et al., 2014). Apesar de ser uma atividade de grande importância na pecuária brasileira, a maioria das criações de pequenos ruminantes, em especial da região Nordeste, ainda é feita de forma extensiva e rústica, sem controle sanitário, nutricional e reprodutivo dos rebanhos, resultando em uma baixa produtividade, o que representa um entrave para o avanço desta atividade (Araújo Filho et al., 1999). O cenário atual da criação de caprinos e ovinos possibilita o aparecimento de doenças, resultando em consequências socioeconômicas relevantes no que diz respeito à perda de animais, o que impacta na comercialização dos mesmos e de seus produtos (S. M. Alves, 2018).

Entre as doenças de grande importância na ovinocultura está a Maedi-Visna, contida na lista de enfermidades da OIE (World Organization for Animal Health/Organização Mundial da Saúde Animal) e que se encontra difundida nos rebanhos ovinos de vários países, sendo motivo de restrição no comércio internacional de produtos oriundos desta espécie animal (Mazzinghy et al., 2014).

Tendo em vista o importante crescimento da ovinocultura no país e os impactos que a Maedi-Visna provoca principalmente na criação de ovinos, torna-se relevante abordar as particularidades dessa doença. Neste contexto, esse trabalho constitui-se de uma revisão de literatura que objetiva abordar diferentes aspectos da Maedi-Visna.

\section{Histórico}

O Maedi-Visna vírus (MVV) foi descoberto em uma ovelha por Sigurdsson (1954) na Islândia no início dos anos de 1950, embora os sintomas da doença já tenham sido descritos por este pesquisador na África do Sul, Estados Unidos e na própria Islândia. Na Islândia, é provável que o MVV tenha aparecido após importação de carneiros assintomáticos da Alemanha em 1933, a qual resultou na disseminação para a maioria dos rebanhos (OIE, 2012). Algum tempo depois dessa importação, os pequenos ruminantes começaram a apresentar sintomatologias como paralisia atáxica e comprometimento pulmonar. A grande quantidade de óbitos levou os criadores a perdas inestimáveis, de forma que um intenso abate sanitário foi estabelecido na tentativa de amenizar a incidência da doença no rebanho (Straub, 2004). 
A Maedi-Visna caracteriza-se por uma infecção lenta e progressiva, que atinge pequenos ruminantes, principalmente ovinos. As apresentações clínicas da doença deram origem ao seu nome. "Maedi" significa "dispneia", associada à pneumonia intersticial progressiva e "Visna" significa "prostração" associada à meningoencefalite (Straub, 2004). No princípio, a enfermidade era considerada duas doenças distintas; porém, após estudos de suas etiologias, constatou-se que se tratava do mesmo patógeno, responsável por diferentes manifestações clínicas. Sendo assim, a doença ficou denominada Maedi-Visna (Dawson, 1987; Thormar, 2013).

Ao estudar o agente etiológico da Maedi-Visna, Sigurdsson (1954) criou o termo "vírus lento" ou lentivírus para aquelas infecções causadas por retrovírus, caracterizadas por infecções crônicas de evolução lenta, persistente, progressiva e degenerativa. O vírus da Maedi-Visna foi o primeiro Lentivirus a ser isolado e caracterizado (Straub, 2004; Thormar, 2013).

\section{Agente etiológico}

O agente causador da Maedi-Visna é um vírus pertencente à família Retroviridae, subfamília Orthoretrovirinae e ao gênero Lentivirus (Pasick, 1998). Esse vírus tem uma grande semelhança com o vírus da Artrite Encefalite Caprina (CAEV) e ambos infectam tanto caprinos como ovinos e, por isso, são chamados comumente de lentivírus dos pequenos ruminantes (Alves \& Pinheiro, 1997; Gomez-Lucia et al., 2013; Lamara et al., 2013). Como os outros lentivírus, o vírus da Maedi-Visna apresenta-se como partículas esféricas, envelopadas com diâmetro variando de 80 a 100nm, com núcleo cônico e denso, onde estão inseridas duas moléculas idênticas de RNA fita simples, uma molécula de transcriptase reversa dependente de magnésio e proteínas do nucleocapsídeo (Gonda et al., 1986). O envelope viral encontra-se associado covalentemente com as glicoproteínas transmembranárias e de superfície. A partícula viral ainda contém outra estrutura chamada de matriz que fica situada entre o envelope e o capsídeo (Straub, 2004). A estrutura viral possui, em sua superfície, hidratos de carbono (ácido salicílico) que desempenham ação de evasão do sistema de defesa do hospedeiro (Mazzinghy et al., 2014).

No genoma viral, são identificadas duas regiões terminais não codificadoras, dentre elas estão os genes codificadores de proteínas estruturais ( $g a g$ e env) e de enzimas ( $p o l$ ). O gene gag codifica grupos específicos de antígenos e o gene env codifica as glicoproteínas de superfície responsável pela ligação do antígeno ao receptor celular. O gene pol codifica as proteínas de atividade enzimática, transcriptase reversa, protease, integrase e dUTpase. A transcriptase reversa é a enzima responsável pela transcrição do RNA viral para o DNA proviral, que irá integrar-se ao genoma da célula hospedeira (Clements \& Payne, 1994). O DNA proviral contém sequências terminais de repetições não codificadoras, as long terminal repeats (LTRs), que têm elementos promotores que iniciam a transcrição do DNA e desempenham um papel importante no tropismo celular e na patogênese (Gomez-Lucia et al., 2018).

O DNA viral apresenta ainda outros genes denominados genes de regulação, entre eles estão: tat, vif, e ver. tat e ver codificam proteínas que regulam a expressão gênica e vif fazem o controle da produção de partículas virais infecciosas. A vif facilita ainda a infectividade e a disseminação do vírus principalmente em linfócitos e macrófagos (Clements \& Payne, 1994). Os genes de regulação tat, ver e vif são referenciados como fases abertas de leitura ("open reading frames" ou "ORFs") e codificam proteínas não estruturais responsáveis pela regulação da replicação viral (Pépin et al., 1998). Além desses, o vírus tem ainda duas relevantes proteínas: a glicoproteína de envelope gp135 e a nucleoproteína p28, que levam a formação de anticorpos nos animais infectados (Brellou et al., 2007).

O MVV é pouco resistente às condições ambientais. Em secreções como colostro e leite de animais infectados, ele é inativado a $56^{\circ} \mathrm{C}$. Por ser um vírus que contém em sua estrutura um frágil envelope lipoproteico, pode-se dizer que ele é sensível também às ações de vários produtos químicos, sendo facilmente inativado por fenóis, detergentes, compostos quaternários de amônio, formalina e hipoclorito de sódio (Silva \& Lima, 2007).

\section{Transmissão}

O reservatório e a fonte de infecção do MVV são os animais infectados, os quais transmitem o vírus por meio de secreções ou excreções ricas em células do sistema monocítico fagocitário (Adams et al., 1983; Guiguen et al., 1990; Pittavino et al., 2014). A transmissão dessa doença pode ser por via 
horizontal ou vertical. A transmissão horizontal do vírus ocorre pelo contato deste agente com as mucosas do animal, tanto pela aspiração de aerossóis pela via respiratória (Zink \& Johnson, 1994), como pela via digestiva com a ingestão de colostro ou leite de fêmeas infectadas (Rowe et al., 1992), além do contato direto entre animais contaminados (Cortez-Romero et al., 2013). A principal forma de transmissão é a horizontal, sendo o conhecimento a respeito da dinâmica desta transmissão de fundamental importância na elaboração de medidas de controle eficazes contra a doença (CortezRomero et al., 2013).

Segundo Gregory et al. (2011), o vírus já foi detectado no sêmen de reprodutores infectados, sugerindo a via reprodutiva como uma provável via de transmissão da Maedi-Visna, visto que a forma de infecção se dá pelo contato do vírus com mucosas, incluindo, desta forma, a transmissão por monta natural ou pela utilização do sêmen contaminado na inseminação artificial. A possibilidade de transmissão pela via reprodutiva ganhou importância entre as formas de transferência do vírus, devido ao uso cada vez mais frequente da reprodução assistida como a inseminação artificial e técnicas de transferência de embriões em pequenos ruminantes (Mazzinghy et al., 2014).

A transmissão vertical é a característica chave da epidemiologia do MVV e inclui infecção hereditária, congênita e no momento do parto (OIE, 2012). Pépin et al. (1998) descreveram que a transmissão vertical ocorre facilmente entre a mãe e o cordeiro por via transplacentária ou intrauterina, uma vez que o vírus é encontrado no fluido uterino de fêmeas infectadas. No ambiente externo ao útero, ocorre principalmente durante os primeiros meses de vida, através da ingestão do agente no leite ou colostro de ovelhas infectadas.

A possibilidade de infecção do feto no ambiente uterino foi relatada por López et al. (2012) ao realizar análises de amostras fetais obtidas entre 50 e 145 dias de gestação, constatando a possibilidade de infecção intrauterina. Outros meios de contaminação foram registrados com agulhas, tatuadores e material cirúrgico sem esterilização e, linha de ordenha inadequada (animais positivos ordenhados antes de negativos) (Pinheiro et al., 2003).

Devido aos riscos de transmissão horizontal e/ou vertical das lentiviroses, países buscam rebanhos livres do lentivírus e de outros agentes patogênicos, facilitando, desta forma, o intercâmbio e certificação de animais, embriões e sêmen desprovidos de agentes causadores de doenças (Cortez-Romero et al., 2013). Estudos têm demonstrado que a transmissão horizontal é a mais importante rota para a manutenção do vírus no rebanho, ocorrendo mais facilmente em criações com alta densidade populacional devido à exposição permanente a animais soropositivos (Alves, 2018).

\section{Epidemiologia}

Entre as doenças de grande importância na ovinocaprinocultura está a Maedi-Visna, uma enfermidade apresentada na lista de notificação compulsória da Organização Mundial da Saúde Animal (OIE) e que se encontra disseminada nos rebanhos ovinos de vários países, justificando o controle no comércio internacional de produtos oriundos dessas espécies animais (Giangaspero et al., 2011; Mekonnen et al., 2010). Na atualidade, o vírus da Maedi-Visna está largamente disseminado pelo mundo, com exceção da Austrália e da Nova Zelândia, dois grandes produtores de ovinos, onde a doença nunca foi reportada (Greenwood et al., 1995). Na Islândia, também não há a ocorrência da doença, pois foi erradicada em 1965 após uma campanha de controle e erradicação que foi realizada durante cerca de 30 anos (Pétursson, 1994). No Brasil, os primeiros relatos da presença do MVV foram feitos por Dal Pizzol, em 1988 e 1989, no estado do Rio Grande do Sul, associados ao histórico de importação de animais oriundos de países nos quais o vírus havia sido detectado (Raymundo Rizaldo Pinheiro et al., 2001). Nos últimos anos, tem sido registrada a ocorrência de ovinos soropositivos em vários estados do Brasil, entre eles: Minas Gerais (Dorneles et al., 2020), São Paulo (Lombardi et al., 2009), Sergipe (Alves, 2018; Mendonça et al., 2013), Pernambuco (Oliveira et al., 2006), Ceará (lves, 2018; Martins et al., 2014), Rio Grande do Norte e Paraíba (Alves, 2018), Bahia (Martinez et al., 2011), Espírito Santo (Barioni et al., 2009).

Por ser uma doença de notificação obrigatória importante para a OIE e que traz prejuízos para a atividade da ovinocultura no mundo, inclusive no Brasil, a Maedi-Visna também está contemplada no Programa Nacional de Sanidade dos Caprinos e Ovinos, instituído pelo Ministério da Agricultura, 
Pecuária e Abastecimento (Pinheiro et al., 2003; MAPA, 2004). As investigações epidemiológicas que fazem parte deste programa são essenciais para avaliar o risco de ocorrência e disseminação da doença nos rebanhos caprino e ovino.

\section{Patogenia}

O MVV acomete especialmente os pulmões, úbere, articulações e cérebro. No entanto, já foram identificados em gânglios linfáticos, baço, medula óssea, rins e terceira pálpebra (Angelopoulou et al., 2006; Capucchio et al., 2003; Preziuso et al., 2003). Esse vírus, ao entrar no organismo, atinge a circulação e começa a desenvolver mecanismos para sobrevivência frente à ação do sistema imunológico do animal (Cortez-Romero et al., 2013).

As células da linhagem monocítico-fagocitária são os alvos de preferência do MVV, pois são nessas células que o vírus se adere ao genoma celular. No entanto, somente após a maturação dos monócitos a macrófagos é que a expressão do gene é ativada. No decorrer da migração dessas células do sangue para os tecidos, pode acontecer a ativação da transcrição com produção de proteínas virais. Após a diferenciação dos monócitos em macrófagos, estes se tornam responsáveis pela disseminação do vírus para todo o organismo do animal (Gendelman et al., 1986).

$\mathrm{O}$ vírus pode permanecer em estado de latência dentro dos macrófagos por tempo indeterminado (Christodoulopoulos et al., 2006). Os macrófagos infectados com o vírus recrutam linfócitos atuando como apresentador de antígeno às células e em seguida aos linfócitos T citotóxicos CD8+ (Lee et al., 1994). A replicação viral cursa com a produção de anticorpos e citocinas, como IL-1 e TNF, que implicam no desenvolvimento das alterações imunopatológicas que acontecem nos órgãos-alvo (DeMartini et al., 1993; Legastelois et al., 1996). A capacidade de replicar em macrófagos e a dependência de replicação viral na maturação celular se tornam elementos cruciais na patogênese dessa doença (Lairmore et al., 1987). Os mecanismos para persistência da infecção desenvolvidos pelos Lentivirus diante da resposta imune do hospedeiro envolvem: capacidade dos monócitos de conter provírus integrado em seu genoma sem ser detectado pelo sistema imune, pois a expressão do gene viral só é ativada no momento em que os monócitos maturam para macrófagos (Brodie et al., 1995); capacidade de infectar persistentemente macrófagos, sem causar lise celular, sendo capaz de disseminar

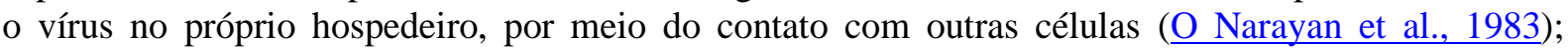
suspensão do ciclo viral pelo processamento incompleto da glicoproteína de superfície (Chebloune et al., 1996); replicação de variantes antigênicos na existência de anticorpos neutralizantes (William P Cheevers et al., 1991; McGuire et al., 1988); produção insuficiente de anticorpos neutralizantes e de Interferon, o que minimiza o índice de replicação e propicia a persistência do estímulo antigênico (Bertoni et al., 1994; Cheevers et al., 1993; Narayan et al., 1984).

Sob outra perspectiva, a existência de ácido siálico na superfície da partícula viral que dificulta a ação dos anticorpos neutralizantes (Huso et al., 1988) e a grande capacidade de mutabilidade do agente que pode tornar-se em variantes antigênicas, servem como mecanismos de escape da resposta celular e humoral (Cheevers et al., 1993; Lichtensteiger et al., 1993). A persistência de antígenos virais e a interação com anticorpos, formando imunocomplexos, favorecem a progressão da doença (Brodie et al., 1995; Mdurvwa et al., 1994; Perry et al., 1995), uma vez que as respostas humorais não conseguem impedir a ação do vírus no organismo do animal (Bertoni et al., 1994).

Segundo Gomez-Lucia et al. (2018), ovelhas e cabras respondem diferentemente à infecção. Esses autores sugerem que em ovinos a presença de anticorpos no úbere pode diminuir a detecção de DNA proviral, o que parece não acontecer em cabras. Sendo assim, os autores sugerem que os anticorpos presentes no leite das ovelhas podem neutralizar o vírus ali presente.

\section{Sinais clínicos}

Os animais infectados são, geralmente, assintomáticos. Ainda assim, apresentam sinais clínicos persistentes, capazes de causar afecção multissistêmica, comumente de evolução crônica, com agravamento gradual das lesões, apresentando perda de peso e debilidade até a morte. A doença pode se apresentar sob quatro formas clínicas principais: respiratória, nervosa, artrítica e mamária, sendo que estas podem apresentar-se juntas ou separadas (Dawson, 1987; Narayan \& Cork, 1985; Peretz et al., 1993). 
A forma mais comum da doença é a respiratória, podendo ocorrer tanto em animal jovem quanto em adulto. Nessa forma, os animais podem apresentar tosse, dispneia, principalmente após esforços físicos, taquipneia, consolidação pulmonar, som úmido a auscultação, associados a quadros de pneumonia intersticial crônica. A princípio, o animal apresenta atraso da marcha ao se mover, seguida de extensão do pescoço com respiração abdominal e dilatação de narinas. Há um comprometimento geral do estado do animal com perda da condição corporal e na fase final da doença culminam em decúbito e morte (Dawson, 1987; Narayan \& Cork, 1985; Sims et al., 1983).

A forma nervosa tem sido relatada em ovinos adultos em consequência de complicações da forma respiratória (Narayan \& Cork, 1985), podendo apresentar-se como incoordenação, andar em círculos, postura anormal da cabeça, nistagmo, paresia gradual do membro posterior que progride para paralisia e morte (Dawson, 1980). Há também sinais nervosos por consequências de complicações da forma artrítica, tendo sido relatados em animais com idade inferior a quatro meses e, raramente, em animais mais velhos. Nesse caso, os animais acometidos podem apresentar ataxia secundária uni ou bilateral, incoordenação, que pode evoluir para um quadro de cegueira, balanceios de cabeça e paralisia facial, podendo levar o animal a morte (Ramírez et al., 2012).

A forma artrítica, embora muito pouco frequente em ovinos, inicia-se com uma sinovite, levando a claudicação e inchaço das articulações, principalmente das articulações carpianas de animais adultos (Dawson, 1980). Essa forma é mais frequente em caprinos e pode ser confundida com a Artrite Encefalite Caprina (CAE) que também é uma lentivirose (Narayan \& Cork, 1985).

Com relação à forma mamária, esta se caracteriza pela presença de nódulos no úbere revelados por palpação, progredindo de forma difusa. Esses nódulos possuem aspecto firme, caracterizando o quadro de mastite indurativa (Van der Molen et al., 1985).

Apesar de todos esses sinais, na maioria das vezes, ao longo da doença, os animais se mantêm alerta e apresentam normorexia, porém com perda de peso (Zachary et al., 2012).

\section{Características anátomo histopatológicas}

Na necropsia de um animal acometido por Maedi-Visna, pode-se observar pneumonia grave, sem colabamento dos pulmões à abertura do tórax. Os pulmões podem apresentar-se dilatados, de modo que é possível verificar impressões marcadas das costelas na superfície pleural. Os pulmões ainda podem apresentar aspecto pálido e pesado e os linfonodos traqueobrônquicos mostrarem-se aumentados (Zachary et al., 2012). Microscopicamente, estas lesões são caracterizadas pela infiltração e acúmulo de linfócitos e macrófagos dentro do septo alveolar, caracterizando uma pneumonia intersticial difusa e crônica (Brodie et al., 1998; CFSPH, 2007). Observa-se nos linfonodos hiperplasia folicular generalizada e infiltrado linfoide, que pode ser detectado em praticamente todos os órgãos (Ellis \& DeMartini, 1985).

No sistema nervoso, podem ser identificadas lesões de encefalomielite não supurativa, acompanhada por pleocitose, edema variável, necrose, astrocitose, coroidite e leptomeningite não supurativa, nas substâncias cinzentas e brancas próximo ao epêndima do sistema ventricular do cérebro e canal central da medula espinhal (Ramírez et al., 2012; Zachary et al., 2012). Manguitos perivasculares não supurativos e quadros de desmielinização podem ainda estar presentes (Ramírez et al., 2012; Zachary et al., 2012).

No úbere de uma fêmea acometida, podem ser encontrados, na palpação, nódulos que podem apresentar-se rígidos de acordo com a progressão da doença (Van der Molen et al., 1985). Microscopicamente, é possível verificar obstrução parcial dos ductos lactíferos por proliferação de tecido linfoide (Lujan et al., 1991).

\section{Diagnóstico}

A princípio, o diagnóstico da Maedi-Visna pode ser feito por observações clínicas quando ocorrem sinais de pneumonia, artrite, mastite, encefalite, emagrecimento, associados aos dados epidemiológicos e ao manejo dos animais. Entretanto, por se tratar de uma enfermidade de caráter crônico, na qual a maioria dos animais raramente apresenta sinais clínicos, é recomendado que o diagnóstico dessa doença seja confirmado por meio de exames laboratoriais (Pinheiro et al., 2001). 
O diagnóstico laboratorial da Maedi-Visna pode ser realizado por meio de técnicas diretas e indiretas. São exemplos de técnicas diretas o Isolamento Viral, a Reação em Cadeia da Polimerase (PCR), a Microscopia Eletrônica, a Histopatologia e a Imunohistoquímica, que tem por objetivo identificar o agente em tecidos, secreções ou líquidos corpóreos. As técnicas indiretas baseiam-se na identificação de anticorpos circulantes contra o agente, como a Imunodifusão em Gel de Ágar (IDGA), Enzyme Linked ImmunonoSorbent Assay (ELISA), Reação de imunofluorescência Indireta (RIFI), Dot-Blot (DB) e Western-Blot (WB) (Dantas et al., 2005).

A técnica recomendada pela OIE é a IDGA, utilizada geralmente para triagem de rotina. Esse é o teste mais utilizado para detecção de anticorpos contra os lentivírus e caracteriza-se por ser de alta especificidade, de baixo custo, de fácil aplicabilidade e não exigir equipamentos e instalações sofisticadas (Arruda et al., 2011; Dantas et al., 2005; Varea et al., 2001). Entretanto, esse método tem sensibilidade inferior quando comparado ao ELISA e sua interpretação é subjetiva, demandando experiência do executor (Dantas et al., 2005). Visto que essa técnica apresenta baixa sensibilidade, a identificação de animais na fase inicial da infecção é limitada, uma vez que estes apresentam baixa concentração de anticorpos contra o MVV (Brodie et al., 1998).

O teste da IDGA consiste em reações de precipitação realizada em gel de ágar em uma placa de Petri ou em uma lâmina de microscópio. Uma linha de precipitação aparente se desenvolve entre os poços no ponto em que é alcançada a relação ótima entre antígeno e anticorpo (Pinheiro et al., 2010). A IDGA é um teste que pode ser aplicado para a detecção de anticorpos contra o MVV tanto no soro sanguíneo quanto no colostro de animais infectados, e a presença de anticorpos no colostro pode ser utilizada na detecção da infecção no rebanho (Alkan \& Tan, 1998).

Outro método preconizado pela OIE é o teste de ELISA, sendo este uma alternativa de diagnóstico mais sensível e específico que o IDGA (Dantas et al., 2005). O ELISA é muito utilizado para detecção e/ou quantificação de anticorpos em amostras de soro, sendo a sua especificidade garantida pela qualidade do antígeno que é adsorvido na placa (Madruga et al., 2001). Por ser um teste de alta sensibilidade e reprodutibilidade, o ELISA tornou-se o método de diagnóstico de eleição para testar muitas amostras (Dantas et al., 2005). Além dessa vantagem, outras podem ser citadas como: a estabilidade e o pequeno volume de reagentes utilizados, resultados de natureza quantitativa, de rápida execução, apresenta baixo nível de risco biológico e pode ser usado em estudos epidemiológicos (Tizard, 2014). Diversos testes de ELISA foram desenvolvidos para a detecção de anticorpos contra lentivírus, nos quais são empregados tanto antígenos nativos quanto recombinantes. Dentre eles estão o ELISA direto, indireto, duplo sanduiche direto e o ELISA duplo sanduiche indireto (Knowles Junior, 1997).

No entanto, segundo Dantas et al. (2005), as técnicas moleculares são mais indicadas para o diagnóstico da Maedi-Visna, em especial a PCR, na qual detecta-se a presença do material genético do vírus sem necessidade de nenhuma resposta do organismo, facilitando assim um diagnóstico precoce. Ressalta-se ainda a importância da associação de testes sorológicos e moleculares para um diagnóstico confiável e precoce.

\section{Controle e profilaxia}

Não existe vacina protetora contra a Maedi-Visna e, por isso e mais alguns fatores como ausência de sinais clínicos em animais infectados, necessidade de diagnóstico precoce e a cronicidade da enfermidade, torna-se laborioso e complexo o controle desta doença (Teixeira, 2012). Dessa maneira, o estabelecimento de medidas profiláticas é fundamental para evitar a disseminação da doença, embasadas principalmente na prevenção das diversas formas de transmissão do agente (Bohland \& D’Angelino, 2005).

Os programas de controle e erradicação da infecção por MVV têm sido praticados em diversos países, em geral por adesão voluntária, por meio de testes periódicos nos rebanhos, com isolamento e eliminação dos positivos, separação dos filhotes de fêmeas positivas ao nascimento e a adoção de certas práticas de manejo para prevenir a disseminação do agente (Pinheiro et al., 2010; Stachissini et al., 2007).

A realização periódica de testes sorológicos de rebanho auxilia na redução da exposição dos animais ao vírus com o descarte de animais soropositivos. Os animais que são adquiridos pela propriedade criadora devem ser isolados do rebanho (quarentena) e testados, por métodos sorológicos, com a

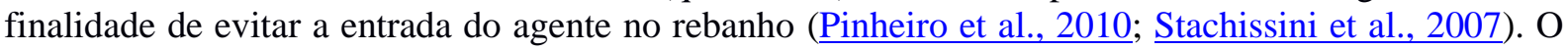


abate de animais positivos em rebanhos com alta prevalência e a substituição por animais soronegativos é uma medida bastante eficaz para reduzir a soro prevalência da doença (Berriatua et al., 2003).

A separação dos recém-nascidos de mães positivas, imediatamente após o nascimento, é uma medida recomendada para prevenir que os filhotes venham a adquirir a doença, visto que uma das formas de transmissão do vírus é a partir da ingestão do colostro da mãe infectada. Sendo assim, é indicado o fornecimento de colostro tratado termicamente a $56^{\circ} \mathrm{C}$ por uma hora ou fornecimento de leite pasteurizado. Essa prática garantiu, durante um programa de controle para a lentivirose, $87 \%$ de soro negatividade do rebanho após um ano de acompanhamento (Stachissini et al., 2007), demonstrando a eficácia desse procedimento para o controle da doença.

Outras medidas profiláticas devem ser adotadas por criadores a fim de evitar a transmissão da doença, a saber: limpeza periódica das instalações, ordenhar as fêmeas soropositivas e/ou suspeitas após as sadias (Oliveira et al., 2006), esterilizar materiais cirúrgicos, como seringas, agulhas, tatuadores entre outros (Callado et al., 2001).

Somente uma medida de controle não é suficiente para controlar a disseminação do vírus no rebanho, portanto, faz-se necessário a associação de todos os métodos de controle citados para evitar a transmissão do agente causador da doença (Pinheiro et al., 2001).

\section{Considerações finais}

A Maedi-Visna representa atualmente um grande desafio, principalmente para a ovinocultura, por não existir vacina e tratamento específico e por ser uma doença que na maioria das vezes é assintomática, o que dificulta o diagnóstico clínico dessa enfermidade, sendo recomendado, portanto, o diagnóstico laboratorial.

Diante das características da Maedi-Visna, é evidente que o principal meio de evitar a disseminação do agente etiológico nos rebanhos ainda é a adoção de práticas de manejo adequadas associadas ao diagnóstico precoce dos animais, com eliminação dos positivos. Se todas as medidas de controle forem adotadas sistematicamente, a doença pode ser gradualmente controlada, com possível evolução para a erradicação.

\section{Referências}

Adams, D. S., Klevjer-Anderson, P., Carlson, J. L., McGuire, T. C., \& Gorham, J. R. (1983). Transmission and control of caprine arthritis-encephalitis virus. American Journal of Veterinary Research, 44(9), 1670-1675.

Alkan, F., \& Tan, M. T. (1998). A comparative study on the diagnosis of maedi-visna infection in serum and colostrum samples using agar gel immunodiffusion (AGID) technique. DTW. Deutsche Tierarztliche Wochenschrift, 105(7), 276-278.

Alves, F. S. F., \& Pinheiro, R. R. (1997). Presença da artrite encefalite caprina a vírus (CAEV) no estado do Maranhão. Congresso Brasileiro de Medicina Veterinária, 25, 278.

Alves, S. M. (2018). Soroprevalência da Maedi-Visna em Ovinos nos estados do Ceará, Rio Grande Do Norte, Paraíba e Sergipe. Semina Ciencias Agrárias, 39(5), 2017-2028.

Angelopoulou, K., Brellou, G. D., \& Vlemmas, I. (2006). Detection of maedi-visna virus in the kidneys of naturally infected sheep. Journal of Comparative Pathology, 134, 329-335. DOI: https://doi.org/10.1016/j.jcpa.2006.01.002

ANUALPEC. (2020). Anuário da Pecuária Brasileira (20th ed., Vol. 1). Instituto FNP.

Araújo Filho, J. A., Carvalho, F. C., \& Silva, N. L. (1999). Criação de ovinos a pasto no semi-árido nordestino. Sobral: Embrapa Caprinos, 1(1), 143-149.

Arruda, E. T., Oliveira, M. M. M., Nascimento, S. A., Campos, A. C., \& Castro, R. S. (2011). Avaliação de uma micrpimunodifusão em gel de ágar para o diagnóstico de Lentevírus de pequenos ruminantes (LVPR) em caprinos. Ciência Animal Brasileira, 12(3), 560-565. DOI: https://doi.org/10.5216/cab.v12i3.12475

Barioni, G., Pereira, L. V., Beltrame, M. A. V., Tesoline, P., \& Gumieiro, M. V. (2009). Soroprevalência de Maedi-Visna em ovinos da raça Santa Inês nos municípios da grande Vitória-ES. Ciência Animal Brasileira, 1, 579-584. DOI: https://doi.org/10.4322/rbcv.2014.080 
Berriatua, E., Álvarez, V., Extramiana, B., González, L., Daltabuit, M., \& Juste, R. (2003). Transmission and control implications of seroconversion to Maedi-Visna virus in Basque dairy-sheep flocks. Preventive Veterinary Medicine, 60(4), 265-279. DOI: https://doi.org/10.1016/S0167$\underline{5877(03) 00163-6}$

Bertoni, G., Zahno, M.-L., Zanoni, R., Vogt, H.-R., Peterhans, E., Ruff, G., Cheevers, W. P., Sonigo, P., \& Pancino, G. (1994). Antibody reactivity to the immunodominant epitopes of the caprine arthritis-encephalitis virus gp38 transmembrane protein associates with the development of arthritis. Journal of Virology, 68(11), 7139-7147. DOI: https://doi.org/10.1128/jvi.68.11.7139-7147.1994

Bohland, E., \& D'Angelino, J. L. (2005). Artrite encefalite caprina: avaliação dos aspectos produtivos e reprodutivos de animais infectados e não infectados. Brazilian Journal of Veterinary Research and Animal Science, 42(2), 81-88. DOI: https://doi.org/10.11606/issn.1678-4456.bjvras.2005.26437

Brellou, G. D., Angelopoulou, K., Poutahidis, T., \& Vlemmas, I. (2007). Detection of maedi-visna virus in the liver and heart of naturally infected sheep. Journal of Comparative Pathology, 136(1), 27-35. DOI: https://doi.org/10.1016/j.jcpa.2006.10.001

Brodie, S. J., Concha-Bermejillo, A., Snowder, G. D., \& DeMartini, J. C. (1998). Current concepts in the epizootiology, diagnosis, and economic importance of ovine progressive pneumonia in North America: a review. Small Ruminant Research, 27(1), 1-17. DOI: https://doi.org/10.1016/s09214488(97)00019-9

Brodie, S. J., Pearson, L. D., Zink, M. C., Bickle, H. M., Anderson, B. C., Marcom, K. A., \& DeMartini, J. C. (1995). Ovine lentivirus expression and disease. Virus replication, but not entry, is restricted to macrophages of specific tissues. The American Journal of Pathology, 146(1), 250-263.

Callado, A. K. C., Castro, R. S., \& Teixeira, M. F. S. (2001). Lentiviruses of small ruminants (CAEV and Maedi-Visna): a review and perspectives. Pesquisa Veterinária Brasileira, 21(3), 87-97. DOI: https://doi.org/10.1590/s0100-736x2001000300001

Capucchio, M. T., Sanna, E., Sanna, M. P., Farigu, S., Minelli, R., \& Guarda, F. (2003). Maedi-Visna virus detection in ovine third eyelids. Journal of Comparative Pathology, 129, 37-43. DOI: https://doi.org/10.1016/s0021-9975(02)00158-5

CFSPH - Center for Food Security \& Public Health. (2007). Disponível em: $<$ https://www.cfsph.iastate.edu/Factsheets/es/maedi-visna-es.pdf>. Acesso em 7/08/ 2020.

Chebloune, Y., Karr, B., Sheffer, D., Leung, K., \& Narayan, O. (1996). Variations in lentiviral gene expression in monocyte-derived macrophages from naturally infected sheep. Journal of General Virology, 77(9), 2037-2051. DOI: https://doi.org/10.1099/0022-1317-77-9-2037

Cheevers, W P, McGuire, T. C., Norton, L. K., Cordery-Cotter, R., \& Knowles, D. P. (1993). Failure of neutralizing antibody to regulate CAE lentivirus expression in vivo. Virology, 196(2), 835-839. DOI: https://doi.org/10.1006/viro.1993.1542

Cheevers, William P, Knowles Junior, D. P., \& Norton, L. K. (1991). Neutralization-resistant antigenic variants of caprine arthritis-encephalitis lentivirus associated with progressive arthritis. Journal of Infectious Diseases, 164(4), 679-685. DOI: https://doi.org/10.1093/infdis/164.4.679

Christodoulopoulos, G., Theodoropoulos, G., Kominakis, A., \& Theis, J. H. (2006). Biological, seasonal and environmental factors associated with Pulex irritans infestation of dairy goats in Greece. Veterinary Parasitology, 137(1-2), 137-143. DOI: http://dx.doi.org/10.1016/j.vetpar.2005.12.012

Clements, J. E., \& Payne, S. L. (1994). Molecular basis of the pathobiology of lentiviruses. Virus Research, 32(2), 97-109. DOI: https://doi.org/10.1016/0168-1702(94)90037-X

Cortez-Romero, C., Pellerin, J. L., Ali-Al-Ahmad, M. Z., Chebloune, Y., Gallegos-Sánchez, J., Lamara, A., Pépin, M., \& Fieni, F. (2013). The risk of small ruminant lentivirus (SRLV) transmission with reproductive biotechnologies: State-of-the-art review. Theriogenology, 79(1), 1-9. DOI: https://doi.org/10.1016/j.theriogenology.2012.09.021

Dantas, T. V. M., Araújo, S. A. C., Silva, J. B. A., Ricarte, A. R. F., \& Teixeira, M. F. S. (2005). Formas de diagnóstico da Maedi-Visna. Ciência Animal, 15(2), 89-97.

Dawson, M. (1980). Maedi/visna: a review. The Veterinary Record, 106(10), 212-216. DOI: https://doi.org/10.1136/vr.106.10.212 
Dawson, M. (1987). Pathogenesis of maedi-visna. Veterinary Record, 120(19), 451-454. DOI: https://doi.org/10.1136/vr.120.19.451

DeMartini, J. C., Brodie, S. J., Concha-Bermejillo, A., Ellis, J. A., \& Lairmore, M. D. (1993). Pathogenesis of lymphoid interstitial pneumonia in natural and experimental ovine lentivirus infection. Clinical Infectious Diseases, 17, 236-242. DOI: https://doi.org/10.1093/clinids/17.supplement 1.s236

Dorneles, E. M. S., Guimarães, A. S., Gouveia, A. M. G., Coura, F. M., Carmo, F. B., Pauletti, R. B., Azevedo, V., Lilenbaum, W., Vitor, R. W. A., \& Pinheiro, R. R. (2020). Seroprevalence of Brucella ovis-epididymitis, smooth-Brucella, leptospirosis, toxoplasmosis, and Maedi-Visna in sheep slaughtered in Minas Gerais State, Brazil. Brazilian Journal of Veterinary Research and Animal Science, $\quad 57(2), \quad$ e164278-e164278. DOI: https://doi.org/10.11606/issn.16784456.bjvras.2020.164278

Ellis, J. A., \& DeMartini, J. C. (1985). Immunomorphologic and morphometric changes in pulmonary lymph nodes of sheep with progressive pneumonia. Veterinary Pathology, 22(1), 32-41. DOI: https://doi.org/10.1177/030098588502200105

Gendelman, H. E., Narayan, O., Kennedy-Stoskopf, S., Kennedy, P. G., Ghotbi, Z., Clements, J. E., Stanley, J., \& Pezeshkpour, G. (1986). Tropism of sheep lentiviruses for monocytes: Susceptibility to infection and virus gene expression increase during maturation of monocytes to macrophages. Journal of Virology, 58(1), 67-74. DOI: https://doi.org/10.1128/jvi.58.1.67-74.1986

Giangaspero, M., Osawa, T., Orusa, R., Frossard, J.-P., Naidu, B., Robetto, S., Tatami, S., Takagi, E., Moriya, H., \& Okura, N. (2011). Epidemiological survey for visna-maedi among sheep in northern prefectures of Japan. Veterinaria Italiana, 47(4), 437-451.

Gomez-Lucia, E., Barquero, N., \& Domenech, A. (2018). Maedi-Visna virus: current perspectives. Veterinary Medicine: Research and Reports, 9, 11-21. DOI: https://doi.org/10.2147/vmrr.s136705

Gomez-Lucia, E., Rowe, J., Collar, C., \& Murphy, B. (2013). Diversity of caprine arthritis-encephalitis virus promoters isolated from goat milk and passaged in vitro. The Veterinary Journal, 196(3), 431438. DOI: http://dx.doi.org/10.1016/j.tvjl.2012.10.023

Gonda, M. A., Braun, M. J., Clements, J. E., Pyper, J. M., Wong-Staal, F., Gallo, R. C., \& Gilden, R. V. (1986). Human T-cell lymphotropic virus type III shares sequence homology with a family of pathogenic lentiviruses. Proceedings of the National Academy of Sciences, 83(11), 4007-4011. DOI: https://doi.org/10.1073/pnas.83.11.4007

Greenwood, P. L., North, R. N., \& Kirkland, P. D. (1995). Prevalence, spread and control of caprine arthritis-encephalitis virus in dairy goat herds in New South Wales. Australian Veterinary Journal, 72(9), 341-345. DOI: https://doi.org/10.1111/j.1751-0813.1995.tb07538.x

Gregory, L., Lara, M., Hasegawa, M. Y., Castro, R. S., Rodrigues, J. N. M., Araújo, J., Keller, L. W., Silva, L. K. F., \& Durigon, E. L. (2011). Detecção do vírus da artrite encefalite caprina no sêmen através das técnicas de PCR e Nested-PCR. Arquivos Do Instituto Biológico, 78(4), 599-603. DOI: https://doi.org/10.1590/1808-1657v78p5992011

Guiguen, F., Lerondelle, C., \& Favier, C. (1990). Réponses du chevreau à des monocytes infectés in vitro par le virus de l'arthrite et de l'encéphalite de la chèvre. Annales de Recherches Veterinaires, 21(3), 179-185.

Huso, D. L., Narayan, O., \& Hart, G. W. (1988). Sialic acids on the surface of caprine arthritisencephalitis virus define the biological properties of the virus. Journal of Virology, 62(6), 19741980. DOI: https://doi.org/10.1128/jvi.62.6.1974-1980.1988

Knowles Junior, D. P. (1997). Laboratory diagnostic tests for retrovirus infections of small ruminants. Veterinary Clinics of North America: Food Animal Practice, 13(1), 1-11. DOI: https://doi.org/10.1016/S0749-0720(15)30361-3

Lairmore, M. D., Akita, G. Y., Russell, H. I., \& DeMartini, J. C. (1987). Replication and cytopathic effects of ovine lentivirus strains in alveolar macrophages correlate with in vivo pathogenicity. Journal of Virology, 61(12), 4038-4042. DOI: https://doi.org/10.1128/jvi.61.12.4038-4042.1987

Lamara, A., Fieni, F., Chatagnon, G., Larrat, M., Dubreil, L., \& Chebloune, Y. (2013). Caprine arthritis 
encephalitis virus (CAEV) replicates productively in cultured epididymal cells from goats. Comparative Immunology, Microbiology and Infectious Diseases, 36(4), 397-404. DOI: http://dx.doi.org/10.1016/j.cimid.2013.02.004

Lee, W. C., McConnell, I., \& Blacklaws, B. A. (1994). Cytotoxic activity against maedi-visna virusinfected macrophages. Journal of Virology, 68(12), 8331-8338. DOI: https://doi.org/10.1128/jvi.68.12.8331-8338.1994

Legastelois, I., Cordier, G., Cozon, G., Cadoré, J. L., Guiguen, F., Greenland, T., \& Mornex, J. F. (1996). Visna-maedi virus-induced expression of interleukin-8 gene in sheep alveolar cells following experimental in vitro and in vivo infection. Research in Virology, 147, 191-197. DOI: https://doi.org/10.1016/0923-2516(96)80234-2

Lichtensteiger, C. A., Cheevers, W. P., \& Davis, W. C. (1993). CD8+ cytotoxic T lymphocytes against antigenic variants of caprine arthritis-encephalitis virus. Journal of General Virology, 74(10), 2111 2116. DOI: https://doi.org/10.1099/0022-1317-74-10-2111

Lombardi, A. L., Nogueira, A. H. C., Feres, F. C., Paulo, H. P., Castro, R. S., Feitosa, F. L. F., Cadioli, F. A., Peiró, J. R., Perri, S. H. V., \& Lima, V. F. M. (2009). Soroprevalência de Maedi-Visna em ovinos na região de Araçatuba, SP. Arquivo Brasileiro de Medicina Veterinária e Zootecnia, 61(6), 1434-1437. DOI: https://doi.org/10.1590/s0102-09352009000600025

López, G. A., Rodríguez, H. A. M., \& Pérez, J. T. (2012). Detección de anticuerpos contra lentivirus de pequeños rumiantes en fetos ovinos y caprinos. Veterinaria México, 43(1), 9-15.

Lujan, L., García, J. F. M., Fernández, D. L., Vargas, A., \& Badiola, J. J. (1991). Pathological changes in the lungs and mammary glands of sheep and their relationship with maedi-visna infection. The Veterinary Record, 129(3), 51-54. DOI: https://doi.org/10.1136/vr.129.3.51

Madruga, C. R., Araújo, F. R., \& Soares, C. O. (2001). Princípios, padronização e validação de provas sorológicas. In C. R. Madruga, F. R. Araújo, \& C. O. Soares (Eds.), Imunodiagnóstico em Medicina Veterinária. Embrapa Gado de Corte.

Martinez, P. M., Costa, J. N., Souza, T. S., Lima, C. C. V., Costa Neto, A. O., \& Pinheiro, R. R. (2011). Prevalência sorológica da Maedi-Visna em rebanhos ovinos damicrorregião de Juazeiro-Bahia por meio do teste de imunodifusão em gel de ágar. Ciência Animal Brasileira, 12(2), 322-329. DOI: https://doi.org/10.5216/cab.v12i2.4454

Martins, G. R., Teixeira, M. F. S., Barroso, I. C., Souza, K. C., Marinho, R. C., \& Junior, R. Q. B. (2014). Detecção do vírus Maedi-visna, por Nested-PCR, no lavado bronco-alveolar de pulmões ovinos provenientes de abatedouro da região metropolitana de Fortaleza. Brazilian Journal of Veterinary Medicine, 36(3), 312-316.

Mazzinghy, C. L., Almeida, K. S., Aalves, F. L., Castro, R. S., Veschi, J. L. A., \& Silva, M. A. G. (2014). Maedi-visna em ovinos: revisão de literatura. Revista Científica Eletrônica de Medicina Veterinária, 12(23), 1-21.

McGuire, T. C., Norton, L. K., O'Rourke, K. I., \& Cheevers, W. P. (1988). Antigenic variation of neutralization-sensitive epitopes of caprine arthritis-encephalitis lentivirus during persistent arthritis. Journal of Virology, 62(9), 3488-3492. DOI: https://doi.org/10.1128/jvi.62.9.3488-3492.1988

Mdurvwa, E. G., Ogunbiyi, P. O., Gakou, H. S., \& Reddy, P. G. (1994). Pathogenic mechanisms of caprine arthritis-encephalitis virus. Veterinary Research Communications, 18(6), 483-490. DOI: https://doi.org/10.1007/BF01839425

Mekonnen, G. A., Sirak, A., \& Chaka, H. (2010). Sero-epidemiological study on Maedi-Visna in selected areas of Ethiopia. Ethiopian Veterinary Journal, 14(1), 101-112. DOI: https://doi.org/10.4314/evj.v14i1.63873

Mendonça, C. E. D., Barros, S. L. B., Mendonça, M. A. D., Guimarães, V. A. A., \& Pinheiro, R. R. (2013). Ocorrência de anticorpos contra o vírus Maedi-Visna em ovinos Santa Inês, no estado de Sergipe, Brasil. Arquivos Do Instituto Biológico, 80(3), 346-351. DOI: https://doi.org/10.1590/s1808-16572013000300013

Narayan, O, Kennedy-Stoskopf, S., Sheffer, D., Griffin, D. E., \& Clements, J. E. (1983). Activation of caprine arthritis-encephalitis virus expression during maturation of monocytes to macrophages. 
Infection and Immunity, 41(1), 67-73. DOI: https://doi.org/10.1128/iai.41.1.67-73.1983

Narayan, O, Sheffer, D., Griffin, D. E., Clements, J., \& Hess, J. (1984). Lack of neutralizing antibodies to caprine arthritis-encephalitis lentivirus in persistently infected goats can be overcome by immunization with inactivated Mycobacterium tuberculosis. Journal of Virology, 49(2), 349-355. DOI: https://doi.org/10.1128/jvi.49.2.349-355.1984

Narayan, Opendra, \& Cork, L. C. (1985). Lentiviral diseases of sheep and goats: chronic pneumonia leukoencephalomyelitis and arthritis. Reviews of Infectious Diseases, 7(1), 89-98. DOI: https://doi.org/10.1093/clinids/7.1.89

OIE - Organização Mundial De Saúde Animal (2012) World manual health situation. Disponível em: <http://www.oie.int/animal-health-in-the-world/oie-listed-diseases-2012/>. Acesso em 25/06/2020.

Oliveira, M. M. M., Castro, R. S., Carneiro, K. L., Nascimento, S. A., Callado, A. K. C., Alencar, C. S. A., \& Costa, L. S. P. (2006). Anticorpos contra lentivírus de pequenos ruminantes em caprinos e ovinos em abatedouros do estado de Pernambuco. Arquivo Brasileiro de Medicina Veterinária e Zootecnia, 58(5), 947-949. DOI: https://doi.org/10.1590/S0102-09352006000500035

Pasick, J. (1998). Maedi-visna virus and caprine arthritis-encephalitis virus: distinct species or quasispecies and its implications for laboratory diagnosis. Canadian Journal of Veterinary Research, 62(4), 241-244.

Pépin, M., Vitu, C., Russo, P., Mornex, J.-F., \& Peterhans, E. (1998). Maedi-visna virus infection in sheep: a review. Veterinary Research, 29(3/4), 341-367. DOI: https://doi.org/10.1016/S09284249(98)80032-1

Peretz, G., Asso, J., \& Devillechaise, P. (1993). CAEV [Caprine Arthritis Encephalitis Virus]: a review and practical applications. Revue de Medecine Veterinaire, 144, 93-98.

Perry, L. L., Wilkerson, M. J., Hullinger, G. A., \& Cheevers, W. P. (1995). Depressed CD4+ T lymphocyte proliferative response and enhanced antibody response to viral antigen in chronic lentivirus-induced arthritis. Journal of Infectious Diseases, 171(2), 328-334. DOI: https://doi.org/10.1093/infdis/171.2.328

Pétursson, G. (1994). Experience with visna virus in Iceland. Annals of the New York Academy of Sciences, 724(1), 43-49. DOI: https://doi.org/10.1111/j.1749-6632.1994.tb38894.x

Pinheiro, R R, Andrioli, A., Gouveia, A. M. G., Aragão, M. A. C., \& Martinez, P. M. (2010). Avaliação de antígenos para o diagnóstico de lentivírus em rebanho caprino sob programa de controle. Arquivos Do Instituto Biológico, 77(1), 133-137. DOI: https://doi.org/10.1590/1808-1657v77p1332010

Pinheiro, Raymundo Rizaldo, Chagas, A. C. S., Andrioli, A., \& Alves, F. S. F. (2003). Viroses de pequenos ruminantes. Embrapa Caprinos Sobral.

Pinheiro, Raymundo Rizaldo, Gouveia, A. M. G., \& Alves, F. S. F. (2001). Prevalência da infecção pelo vírus da artrite encefalite caprina no estado do Ceará, Brasil. Ciência Rural, 31(3), 449-454. DOI: https://doi.org/10.1590/s0103-84782001000300014

Pittavino, M., Ferreri, L., Giacobini, M., Bertolotti, L., Rosati, S., \& Venturino, E. (2014). A CAEV epidemiological model for goat breeding. Applied Mathematics and Computation, 227(0), 156-163. DOI: http://dx.doi.org/10.1016/j.amc.2013.11.030

Preziuso, S., Taccini, E., Rossi, G., Renzoni, G., \& Braca, G. (2003). Experimental Maedi Visna Virus infection in sheep: a morphological, immunohistochemical and PCR study after three years of infection. European Journal of Histochemistry, 47(4), 373-378. DOI: https://doi.org/10.4081/849

Ramírez, H., Reina, R., Bertolotti, L., Cenoz, A., Hernández, M.-M., San Román, B., Glaria, I., de Andrés, X., Crespo, H., \& Jáuregui, P. (2012). Study of compartmentalization in the visna clinical form of small ruminant lentivirus infection in sheep. BMC Veterinary Research, 8(1), 8. DOI: https://doi.org/10.1186/1746-6148-8-8

Rowe, J. D., East, N. E., Thurmond, M. C., Franti, C. E., \& Pedersen, N. C. (1992). Cohort study of natural transmission and two methods for control of caprine arthritis-encephalitis virus infection in goats on a California dairy. American Journal of Veterinary Research, 53(12), 2386-2395.

Sigurdsson, B. (1954). Maedi, a slow progressive pneumonia of sheep: an epizoological and a pathological study. British Veterinary Journal, 110(7), 255-270. DOI: 
https://doi.org/10.1016/s0007-1935(17)50273-0

Silva, J. B. A., \& Lima, P. M. (2007). Lentivírus de pequenos ruminantes: caracterização etiológica, infectividade, controle, prevenção e diagnóstico. Acta Veterinaria Brasilica, 1(4), 111-117.

Sims, L. D., Hale, C. J., \& McCormick, B. M. (1983). Progressive interstitial pneumonia in goats. Australian Veterinary Journal, 60(12), 368-371. DOI: https://doi.org/10.1111/j.17510813.1983.tb02850.x

Stachissini, A. V. M., Modolo, J. R., Castro, R. S., Leite, B. L. S., Araújo Júnior, J. P., \& Padovani, C. R. (2007). Controle da Artrite-Encefalite Caprina, em um capril comercial endemicamente contaminado. Brazilian Journal of Veterinary Research and Animal Science, 44(1), 40-43. DOI: https://doi.org/10.11606/issn.1678-4456.bjvras.2007.26659

Straub, O. C. (2004). Maedi-Visna virus infection in sheep. History and present knowledge. Comparative Immunology, Microbiology and Infectious Diseases, 27(1), 1-5. DOI: https://doi.org/10.1016/S0147-9571(02)00078-4

Teixeira, W. C. (2012). Soroprevalência de lentiviroses de pequenos ruminantes e caracterização dos rebanhos caprinos e ovinos no estado do Maranhão, Brasil. In Animal Science: Vol. PhD. Universidade Federal Rural de Pernambuco.

Thormar, H. (2013). The origin of lentivirus research: Maedi-visna virus. Current HIV Research, 11(1), 2-9. DOI: https://doi.org/10.2174/1570162x11311010002

Tizard, I. R. (2014). Imunologia Veterinária: introdução. Editora Roca.

Van der Molen, E. J., Vecht, U., \& Houwers, D. J. (1985). A chronic indurative mastitis in sheep, associated with maedi/visna virus infection. Veterinary Quarterly, 7(2), 112-119. DOI: https://doi.org/10.1080/01652176.1985.9693966

Varea, R., Monleon, E., Pacheco, C., Lujan, L., Bolea, R., Vargas, M. A., Van Eynde, G., Saman, E., Dickson, L., \& Harkiss, G. (2001). Early detection of maedi-visna (ovine progressive pneumonia) virus seroconversion in field sheep samples. Journal of Veterinary Diagnostic Investigation, 13(4), 301-307. DOI: https://doi.org/10.1177/104063870101300404

Zachary, J. F., McGavin, D., \& McGavin, M. D. (2012). Bases da patologia em veterinária. Elsevier Brasil.

Zink, M. C., \& Johnson, L. K. (1994). Pathobiology of lentivirus infections of sheep and goats. Virus Research, 32(2), 139-154. DOI: https://doi.org/10.1016/0168-1702(94)90039-6

Histórico do artigo:

Recebido: 7 de agosto de 2020.

Aprovado: 1 de setembro de 2020.

Disponível online: 19 de janeiro de 2021 .
Licenciamento: Este artigo é publicado na modalidade Acesso Aberto sob a licença Creative Commons Atribuição 4.0 (CC-BY 4.0), a qual permite uso irrestrito, distribuição, reprodução em qualquer meio, desde que o autor e a fonte sejam devidamente creditados. 